\title{
Simple tipping or complex transition? Lessons from a green Sahara
}

\author{
Sebastian Bathiany ${ }^{1,2}$, M. Claussen ${ }^{2,3}$, V. Brovkin², M. Scheffer ${ }^{1}$, V. Dakos ${ }^{4}$ and E. van Nes
}

\begin{abstract}
The history of the Sahara provides an example for our changing perspective on abrupt change in the Earth system. The emerging concepts can help us to understand past transitions and assess potential future tipping points.
\end{abstract}

Little does the monotonous and hostile environment of today's Sahara Desert tell us about its colorful past. However, climate and vegetation reconstructions reveal that several thousand years ago, parts of the Sahara resembled a flourishing garden with extensive vegetation and lakes (Jolly et al. 1998). This green Sahara was only the most recent of many green episodes in North Africa's history. The most important driver of these landscape transformations was the permanent change in the Earth's orbital parameters (Kutzbach 1981). When the distance between Earth and Sun is smallest during boreal summer, the larger solar irradiation intensifies the West African monsoon and thus increases rainfall.

\begin{abstract}
While it is obvious that rainfall is beneficial for vegetation, climate models indicate that vegetation can also enhance rainfall. First, the dark vegetation absorbs more sunlight than the bright desert and provides energy for convection (Charney et al. 1975). Second, the evaporation from vegetation and lake surfaces feeds the water back into the atmosphere (Rachmayani et al. 2015). Vegetation and rainfall are therefore linked in a self-amplifying process, a positive feedback. The stronger this feedback, the more abrupt the transition from a green Sahara to a desert (Fig. 1).
\end{abstract}

Whereas orbital parameters change gradually over thousands of years, model results (Claussen et al. 1999) and a dust record from the Atlantic (de Menocal et al. 2000) suggested a quite rapid vegetation loss at the end of the green Sahara. This seemed to support the view of a switch from a green state to a desert state, a natural climate catastrophe comparable to a chair suddenly tipping over when it is slowly tilted. Such tipping points have been found not only in atmosphere-vegetation models (Brovkin et al. 1998), but also in simple models representing ocean circulation, Arctic sea ice, ice shields, savannah and lake ecosystems, and the East Asian and Indian monsoons.

Tipping points in a world of complexity Each tipping point in the simple models mentioned above results from a positive

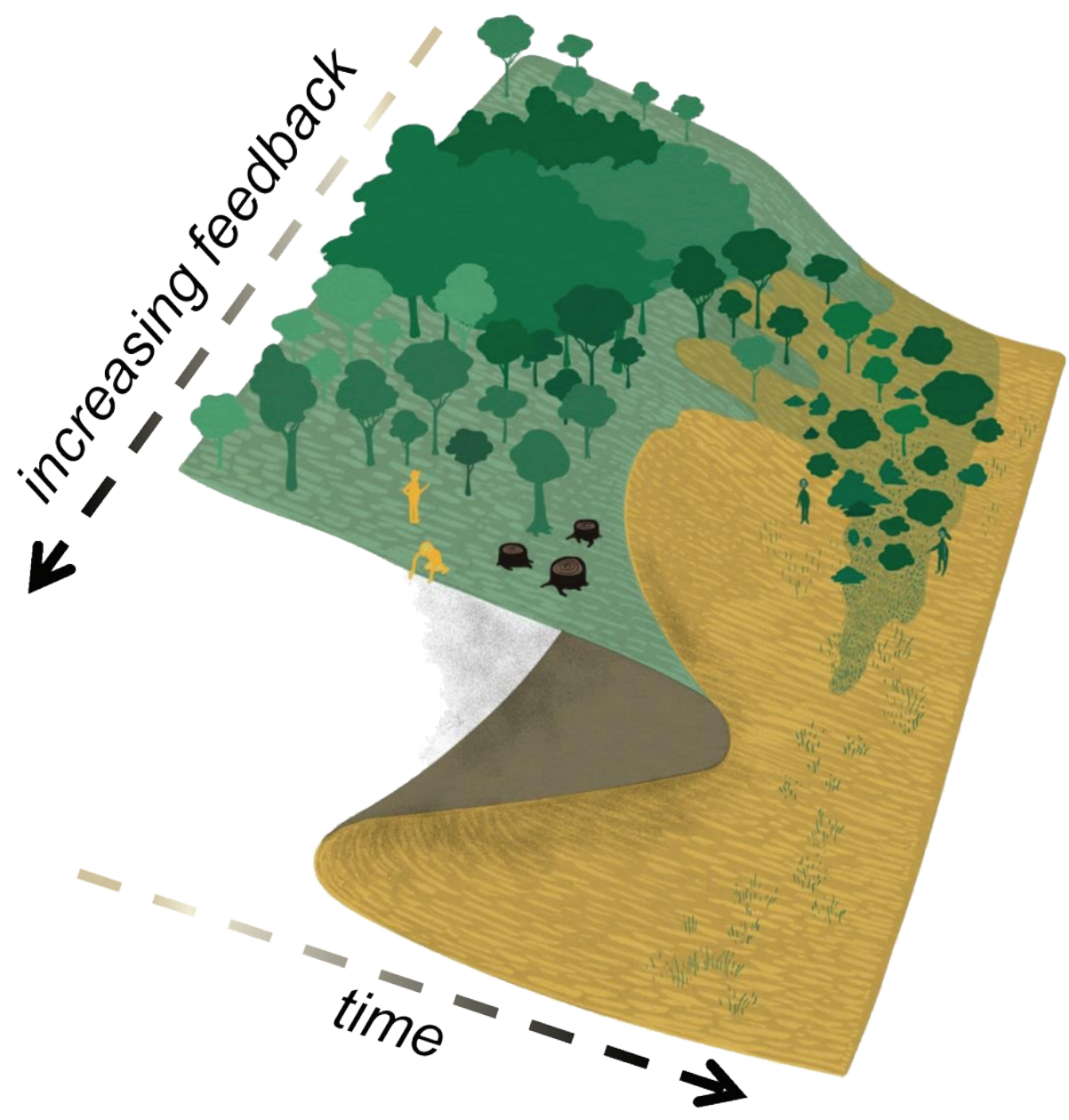

Figure 1: Stability landscape of green Sahara and desert. The larger the atmosphere-vegetation feedback, the sharper the transition between the two states. From: Model Calendar 2015, designed by Elsa Wikander at Azote, funded by the Beijer Institute of Ecological Economics and the Stockholm Resilience Centre. 


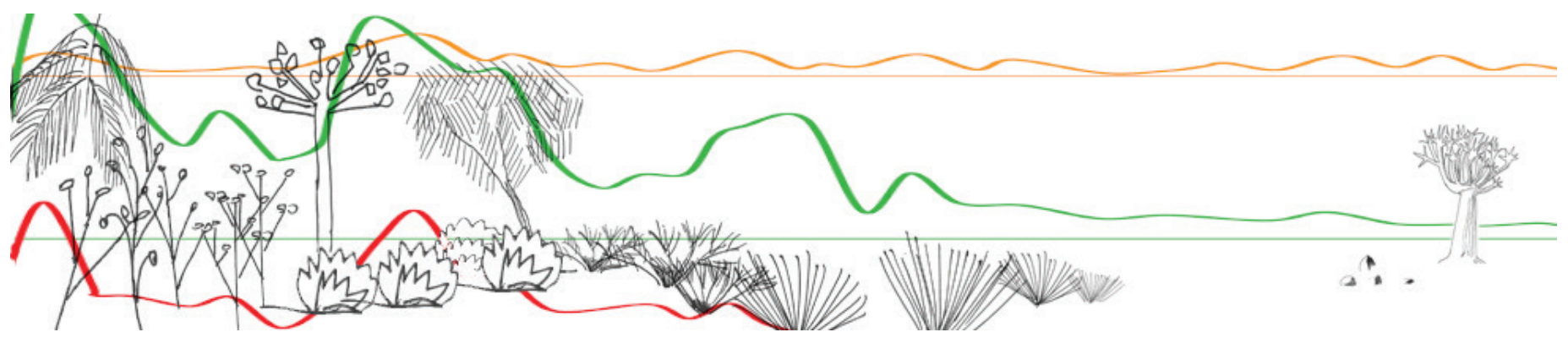

Figure 2: Idealized abundance of East Saharan plant types from 6000 to 3500 years ago (from left to right) with Acacia (orange), Poaceae (green) and tropical plant taxa (red). Pollen records after Kroepelin et al. (2008), drawing by Dominique Donoval, Max Planck Institute for Meteorology, Hamburg.

feedback. However, in reality, the rate of a transition is not a question of feedbacks alone. For instance, fast fluctuations in the weather permanently perturb the vegetation and other slow components of the Earth system. These fluctuations thus superimpose an otherwise smooth transition and can either make it more gradual or even more pronounced (Liu et al. 2006).

Moreover, there are reasons to believe that the spatial heterogeneity of the land surface tends to make transitions smoother on large spatial scales (Brook et al. 2013). Indeed, different records from the Sahara, such as pollen reconstructions from northern Chad (Kroepelin et al. 2008; Fig. 2), suggest a spatially inhomogeneous transition to today's desert and a gradual decrease in rainfall. Theoretical modeling studies confirm that if different locations are only weakly connected or very dissimilar, every location changes with its own timing, and transitions tend to be gradual on large scales (van Nes and Scheffer 2005). Even in the case of a uniform climate, vegetation still consists of different plant types with different moisture requirements, promoting a gradual change in vegetation composition instead of a singular vegetation dieback (Claussen et al. 2013; Fig. 2).

It is therefore quite clear that the Sahara Desert was not born in one synchronized tipping event. Nonetheless, the case of the green Sahara reminds us that we also need to take spatial interactions into account, because the winds and currents in the atmosphere and ocean couple different locations. Naturally, this connection tends to be strongest between adjacent places since properties like water and energy are transported from one place to the next. But large-scale circulation features like the African monsoon or the ocean's overturning circulation can also couple locations very far from each other. Strong links in the network of interactions can synchronize transitions and promote abrupt change far from the origin of its occurrence. An abrupt climate change at a single location may thus trigger a domino effect of climate changes at different locations. The question is therefore not only whether tipping points exist but also whether there are local hotspots where a system is particularly vulnerable (Bathiany et al. 2013).
Finally, neither climate feedbacks nor spatial interactions are required to obtain abrupt change on a local level. First of all, ecological systems can have tipping points of their own (Scheffer et al. 2001), and many physical and biological systems have intrinsic thresholds, like the freezing temperature of water or the wilting point of plants. Secondly, a shift in the position of sharp spatial gradients or circulation patterns can cause abrupt change at a particular location. For example, the gradual spatial shift of the vegetation distribution may locally be seen as a sudden desertification. Abrupt change in paleorecords like the dust record by de Menocal (2000) could thus be interpreted to result from a shift in the desert boundary or the wind direction.

\section{An uncertain future}

In the light of all these mechanisms at play, the reconstructions from the Sahara leave room for interpretation. Has the Sahara taken its green secret to the grave? And are tipping points only a Fata Morgana, caused by oversimplified models? Research on other potential climate tipping points indicates that this may be true. So far, comprehensive climate models cannot convincingly answer the question if largescale climate tipping points are ahead in the near future (Drijfhout et al. 2015). However, there is evidence that abrupt climate changes happened in the Earth's history. The potential damage such events may cause, and the large uncertainty of their occurrence, require us to assess the risk of future abrupt change by improving our scientific understanding.

The crucial questions of this assessment are the same as for the Sahara. What is the balance of the relevant feedbacks? How homogeneous is the system and are there strong spatial connections? What is the interplay between fast variability and slow system components, and what can we learn from the variability? Are there natural thresholds which promote or prevent abrupt change? As the physical or biological processes differ in each case, answers may depend on which potential tipping point is considered. Bridging the gap between the world of tipping point concepts and the world of process understanding will therefore be key to scientific progress. The green Sahara provides an example for this challenge. Even though its decline was overall more gradual than previously thought, it remains a fruitful case study to explore the above questions. Insofar, the green Sahara has not turned to dust, but flowers in a greater context.

\section{AFFILIATIONS}

'Department of Environmental Sciences, Wageningen University, The Netherlands

${ }^{2}$ Max-Planck-Institute for Meteorology, Hamburg, Germany

${ }^{3}$ Meteorological Institute, University of Hamburg, Germany

${ }^{4}$ Center for Adaptation to a Changing Environment, ETH Zürich, Switzerland

\section{CONTACT}

Sebastian Bathiany: sebastian.bathiany@wur.n

\section{REFERENCES}

Bathiany S et al. (2013) Earth Syst Dynam 4: 63-78 Brook B et al. (2013) Trends Ecol Evol 28: 396-401 Brovkin V et al. (1998) J Geophys Res 103: 31613-31624 Charney J et al. (1975) Science 187: 434-435

Claussen M et al. (1999) Geophys Res Lett 26: 2037-2040

Claussen M et al. (2013) Nat Geosci 6: 954-958 de Menocal P et al. (2000) Quat Sci Rev 19: 347-361 Drijfhout SS et al. (2015) PNAS 112: 5777-5786 Jolly D et al. (1998) J Biogeog 25: 1007-1027 Kroepelin S et al. (2008) Science 320: 765-768 Kutzbach JE (1981) Science 214: 59-61 Liu Z et al. (2006) Geophys Res Lett 33, doi:10.1029/2006GL028062

Rachmayani R et al. (2015) Clim Past 11: 175-185 Scheffer M et al. (2001) Nature 413: 591-596 van Nes E, Scheffer M (2005) Ecology 86: 1797-1807 